\title{
Towards building a neural network model for predicting pile static load test curves
}

\author{
A. K. ALZO'UBI, and Farid IBRAHIM \\ College of Engineering, Abu Dhabi University, Al Ain, United Arab Emirates
}

\begin{abstract}
In the United Arab Emirates, Continuous Flight Auger piles are the most widely used type of deep foundation. To test the pile behaviour, the Static Load Test is routinely conducted in the field by increasing the dead load while monitoring the displacement. Although the test is reliable, it is expensive to conduct. This test is usually conducted in the UAE to verify the pile capacity and displacement as the load increase and decreases in two cycles. In this paper we will utilize the Artificial Neural Network approach to build a model that can predict a complete Static Load Pile test. We will show that by integrating the pile configuration, soil properties, and ground water table in one artificial neural network model, the Static Load Test can be predicted with confidence. We believe that based on this approach, the model is able to predict the entire pile load test from start to end. The suggested approach is an excellent tool to reduce the cost associated with such expensive tests or to predict pile's performance ahead of the actual test.
\end{abstract}

\section{Introduction}

Deep foundations such as piles, are the part of a structure used to carry and transfer loads of the superstructure to the bearing ground located at some depth below ground surface. Pile's capacity is one of the most problematic designs in Civil Engineering due to the variability in geomaterials properties and the large number of parameters involved in controlling, or should be involved, in pile's design. In practice, three methods of design are being used: full-scale static load test, analytic methods, and dynamic methods.

There are many factors that contribute to choosing and adapting the most relevant pile design. Some of these factors are size of the project, the significance of the project, and/or the available fund allocated for the investigation, test, and design. Most analytical methods of determining the pile capacity are developed empirically by comparing the results of static load tests with measured soil properties [1]. So, performing the static load tests is essential part of designing these deep foundations or checking their performance especially in the UAE where such test is mandatory.

As a result of the economic boom that has been happening in the United Arab Emirates, construction industry flourished and huge amount of new projects has to be built as fast as possible, keeping in mind the safety of structures such as high rise buildings, malls, and residential developments. With this in mind, engineers relied heavily on the Continuous Flight Auger (CFA) piles (see Figure 1) to speed up the construction process, and over design these piles to avoid failure. The CFA piles are easy and fast to construct in soft ground such as Silty Sand soils which dominates the upper soil layers in the major cities in the UAE. The CFA piles in this region are used to transmit high concentrated loads deep into the ground, mainly by friction. The test load is usually applied in increments up to 1.5 times the design load for working piles load, or more in rare cases, as required by structural designer or geotechnical engineer.

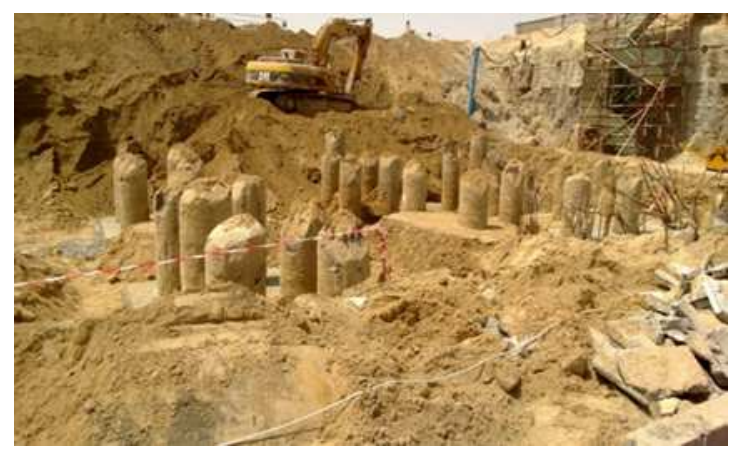

Fig. 1. Piles underneath the future Etisalat centre in Abu Dhabi

In this paper we introduce an Artificial Neural Network framework to build a model that can predict a complete Static Load Pile test. The authors will depend on three factors to reduce the variation of the parameters in the artificial neural Network; the consistency of the geology, the dominant pile diameter, and the number of piles passing the tests. All the tests that are to be used in 
this research are conducted in three major cities (Abu Dhabi, Dubai, and Al Ain) which are located in the United Arab Emirates. This consistency will reduce the variations in the geomaterial parameters, Figure 2 shows an example of the soil profile encountered typically in the field. Moreover, in this research we choose piles with 500 $\mathrm{mm}$ diameter since $80 \%$ of about 100 projects that we explore have a diameter of $500 \mathrm{~mm}$ and lengths between 6 to $16 \mathrm{~m}$. Also, out of the 100 tests, that we explored, passed the test and only one pile has failed to meet the expectation. This single pile exceeds the limit of the acceptable downward movement of $1 \%$ (of its diameter) by moving $1.1 \%$ at three times not 1.5 times the design load. As a result, we will use successful piles only in this research. Based on the above discussion, it is safe to assume that predicting the pile capacity by means of artificial neural networks can be achieved through training the model on the available data. This approach would allow judging new proposed pile design ahead of the field tests. High prediction accuracy and precision can also be achieved through continuous data feeding in the model by using future tests. This eventually will cut the cost of conducting multiple static load test for the same project. In fact, Coduto [1] pointed out that static load tests are much more expensive than analytic methods, and thus the latter is very attractive. However, the calculated load capacities are not as precise, so designs based solely on analytic methods must be correspondingly more conservative and the final design is more expensive.

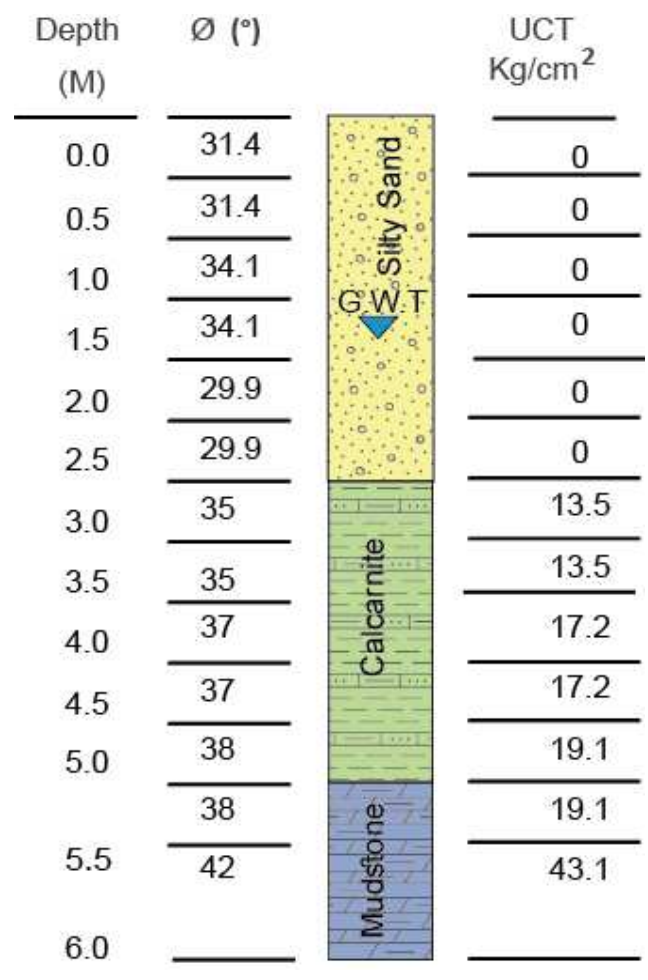

Fig. 2 Static Load test in the future Etisalat centre

\section{Artificial Neural Networks}

The artificial neural network is the most common training model used in many applications. In this model a set of training records with known output are processed by an algorithm to learn the neural network. It consists of three layers; input, hidden and output layers. Each layer is defined as a set of connected units and weights are associated with each connection. Input attributes are fed simultaneously to form the input layer. The weighted input is propagated forward and passed to the second layer which is the hidden layer; one or more hidden layers may be defined. The number of hidden layers is purely empirical and depends on the experiment result.

The output is calculated for each hidden layer until it reaches the output layer, and in this case it is the machine prediction value. This value is compared to the known output value and the error produced is propagated backward by adjusting the weights and biases at each unit to reflect the error in the network prediction. The machine will continue iterating forward and backward learning the values assigned to the weights and biases until it reaches to a corrected predicted output value that is within an acceptable error difference. Once the model is built, it can be used to process newly input records whose output is unknown. The neural network will use the learned values of the weights and biases to predict the unknown output [2].

\section{Related Works}

The use of artificial neural networks in predicting the pile capacity started in the 1990's, when Goh [3] used a form of a model to predict an estimate of the friction capacity of driven piles in clay soils. The results were promising when compared to the actual data and some empirical methods. Lee and Lee [4] tried to predict the driven pile capacity by using an artificial neural network model. The error between the predicted and the actual pile test was around $20 \%$. However, they did not attempt to predict the entire static load test. Abu-Kiefa [5] developed three artificial neural network models to forecast driven piles capacity. He compared the results with four empirical formulas, and found that the model that was devoted to forecast the total pile capacity was more accurate than others with 0.95 coefficients of determination. Furthermore, Goh [6] presented a new neural network model to predict pile capacity in sandy soils. The model's pile capacity was satisfactory when compared to other empirical formulas. Shahin [7] discussed different applications of artificial neural network in Geotechnical Engineering; and mentioned different applications including predicting the pile capacity. Benali and Ammar [8] also used artificial neural network to expect the pile capacity; they used a database of 80 cases collected from the literature and corresponding to different sites distributed all over the world. They reported that the networks are feasible for these kinds of problems but they did not attempt to predict the entire static load test. More recently, Maizir and Kassim [9] used artificial neural networks for predicting the axial capacity of a driven pile; the data collected for this study consisted of 300 cases from several projects in Indonesia and Malaysia. 
He found that a good prediction was achieved if "both stress wave data and properties of both driven pile and driving system are considered in the input data". In another experiment [10], the pile setup was predicted using an artificial neural network model. The predicted values were compared with those produced by some empirical formulas. It showed that the model produced satisfactory results. A recent paper [11] proposed a framework for a system model that combines the neural network technique to predict the pile capacity with the geographic information system (GIS) data. The proposal suggested building a new layer in the GIS containing the pile load tests.

As we can see in the above mentioned studies, no serious attempt was made to predict the entire static load test; in this paper we demonstrate that static load test can be reasonably predicted by an artificial neural network with enough training data.

\section{General Geology}

The United Arab Emirates (UAE) lies on the floor of Arabian Gulf which mainly composed of extensive carbonate sediments. Fookes and Knill [12] divided the mountain and piedmont plain of the Arabian Gulf into four sediment depositions. The coast line of UAE, where this study is performed, is located in zone number four or the base plain. The upper layer deposits of this zone consists of sand dunes, loess, and evaporate together with marine sand and silts. Wind and evaporation, due to high temperature, are the principal transporting agents in this region.

Although wind-blown material tends to predominate, as great quantities of silt and sand are moved during periods of high wind, water also plays an important role in this movement and later deposition of high quantities of Silty Sand material. The depth of the Silty Sand layer ranges from 3 to 10 meters and it has a major role in establishing the pile capacity due to friction. Flash floods, last one was witnessed in 2015, are relatively rare, and any water stream actually reaching zone IV is usually short-lived after the rainstorm. However, the water table is very high and it can be as close as 0.5 meter from the ground surface. This water table can dominate the desert processes by limiting the wind erosion to soils above the water table; wind erosion more or less stops when sand and silts are damp. Moreover, capillary pressure forces water movement from the water table to ground surface as the water table is high and evaporation occurs in high rates.

In these conditions a thick salt crust can build and it might affect the pile's capacity. These deposits are common in the urban areas of UAE desert coastal regions and particularly extensive around this coast line. Beneath the first layers of sand and silt, other soil and rock materials exists. The Sand and Silt deposits cover interbedded sandstones (see Figure 2), conglomerates, calcisiltite, limestone, and siltstones; clay deposits may also be encountered. In this research the piles length in all of the projects that will be included ranges from 6 to 15 meter.

\section{Classification of the Materials and NN}

The field and laboratory test results are summarized for the various ground materials. The sieve analysis and the Atterberg Limits test were performed to classify the soil according to the Unified Soil Classification System and later considered as a parameter in the Neural Network input data to improve the model accuracy. In this research we will classify the soil layers into different layers and then coded to numbers. Table 1 presents example of such coding that shows the soil layers along with the different codes that we used in the artificial neural Network.

Table 1: Example of the coding of soil description that will be adapted in the neural network model.

\begin{tabular}{|l|l|}
\hline Soil Description & Soil Profile \\
\hline $\begin{array}{l}\text { Silty SAND (SM): Dry } \\
\text { to moist, light brown, } \\
\text { fine non-plastic, trace } \\
\text { fine gravel }\end{array}$ & 1 \\
\hline $\begin{array}{l}\text { Poorly graded SAND } \\
\text { with silt (SP-SM): Wet, } \\
\text { light brown, fine, and } \\
\text { non-plastic. }\end{array}$ & 2 \\
\hline $\begin{array}{l}\text { MUDSTONE: Very } \\
\text { weak to weak, } \\
\text { moderately to highly } \\
\text { fractured, moderately } \\
\text { weathered. }\end{array}$ & 3 \\
\hline $\begin{array}{l}\text { MUDSTONE: Weak } \\
\text { moderately fractured, } \\
\text { moderately weathered. }\end{array}$ & 4 \\
\hline $\begin{array}{l}\text { Crystalline Gypsum: } \\
\text { Moderately weak } \\
\text { moderately fractured, } \\
\text { moderately weathered. }\end{array}$ & 5 \\
\hline $\begin{array}{l}\text { Loose to medium dense } \\
\text { SAND with trace silt }\end{array}$ & 6 \\
\hline $\begin{array}{l}\text { Very loose light brown } \\
\text { clayey fine SAND. }\end{array}$ & 7 \\
\hline $\begin{array}{l}\text { Dense, light brown fine } \\
\text { silty SAND }\end{array}$ & 8 \\
\hline
\end{tabular}

\section{Static Load Test}

According to the field and laboratory investigations, subsurface conditions, engineering analysis and practical experience, in all of the projects in this research the recommended type of foundation was CFA piles. Pile load tests are considered the most satisfactory method to assess the carrying capacity of a pile, see Figure 3 which shows the details of a static load test conducted in the field. During the foundation construction period, it is recommended that such tests be performed according to British Standard Code of Practice 8004 on specially constructed piles that are installed before the start of the general construction works. The common practice in the UAE is to test the piles after construction for quality assurance and not for design; i.e. to check performance. As a result of this practice CFA piles, in most cases, are 
over designed to avoid failure in the testing process. However, if testing is carried out for design purposes, significant savings may result from a more economical pile design based upon the specific test data.

Since the theoretical design methods provide an approximate working load, the static load test should demonstrate the pile's performance and its load settlement characteristics. Figure 4, shows the static load test performed in the future Etisalat centre (see figure 1). In the static pile load tests the load-displacement curves were obtained through two cycles of loading-unloading.

As mentioned earlier, the pile load test is usually performed to verify the pile's ultimate capacity. This value is based upon the allowable amount of settlements determined by the requirements of the engineer or a known standard specification. In all of the tests considered in this paper, the BS8004 [13] was used as the testing procedure. The test load is applied in increments up to 1.5 times the design load for working piles load. The load was applied by mean of hydraulic jack as shown in Figure 2, four reaction piles were used to provide support for the loading frame. In addition, four settlement gauges were used to monitor the displacement.

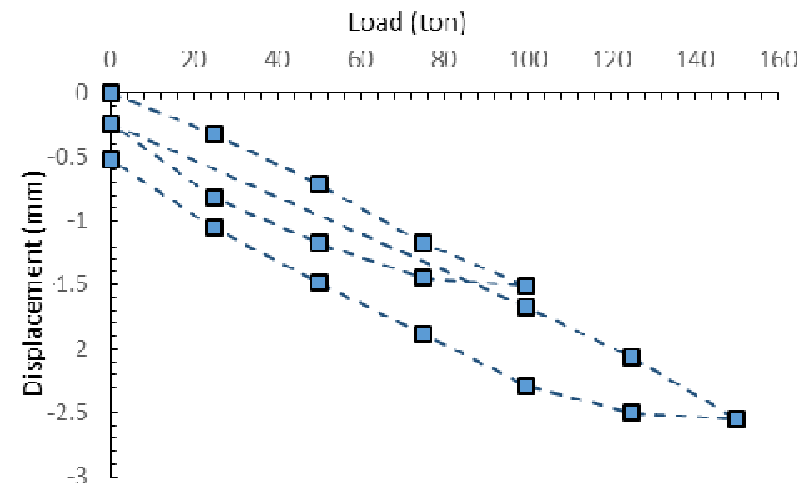

Fig. 3 Field data of a pile static load test

The maintained load method was used in all of the projects. The load was increased in stages and maintained for at least 20 minutes or until the rate of settlement decreased to less than $0.10 \mathrm{~mm} / \mathrm{hr}$, whichever is greater. As a matter of fact, in all of the projects in this research, the load was maintained until settlement has seized. In the first loading cycle, increments of $25 \%$ of the design load -up to the working load- are imposed to the tested pile and maintained until settlement seized. Settlement readings were taken, for each load increment, every 5 minutes until the settlement stopped. In the first unloading cycle, the load was reduced in inducement of $25 \%$ of the testing value until the zero load stage is reached, while settlement was recorded as described above. Reloading was then applied to test pile from zero to the test load (150\% of the design load); first increment from zero to the design load and kept for six hours at which the settlement seized. And then increased in $25 \%$ of the design load until the test load was reached. At last, the unloading occurred in $25 \%$ of the testing load until zero load.
The above mentioned testing procedure is adapted in the majority of tests in the UAE. We rely on this procedure to verify the CFA piles performance ahead of construction. In case the one of the tests failed at a particular site, the CFA piles must be extracted from the ground. This costly solution forced engineers to overdesign the piles to avoid failure in the test. The framework proposed in this paper aims at reducing this cost through predicting the static load test behaviour based on the proposed pile configuration, ground water table, and the soil profile mechanical properties. We believe that those parameters control the CFA piles capacity and performance under loading or unloading.

\section{The Network Model}

The principle underlying this research is that it is possible to predict the displacement value using an artificial neural network that is trained over data consisting of a combination of the soil profile and the pile configuration, as shown in figure 5. Coduto [1] showed that the soil profile and the pile configuration are essential in determining the pile capacity and behaviour under loading and unloading cycles. Hence, if we assume Si to be the set of soil profile values at site $\mathrm{i}$ and whose elements consists of values in the set $\{\mathrm{v} 1, \mathrm{v} 2, \ldots, \mathrm{vj}\}$ and Pi be the set of pile configuration at site $i$, and whose parameters consists of $\{\mathrm{p} 1, \mathrm{p} 2\}$, then it is possible to predict the displacement $\mathrm{D}$ such that $\mathrm{F}(\mathrm{Si}, \mathrm{Pi})=\mathrm{D}$, where $\mathrm{F}$ is a mapping function. This mapping function will be built using a trained artificial neural network.

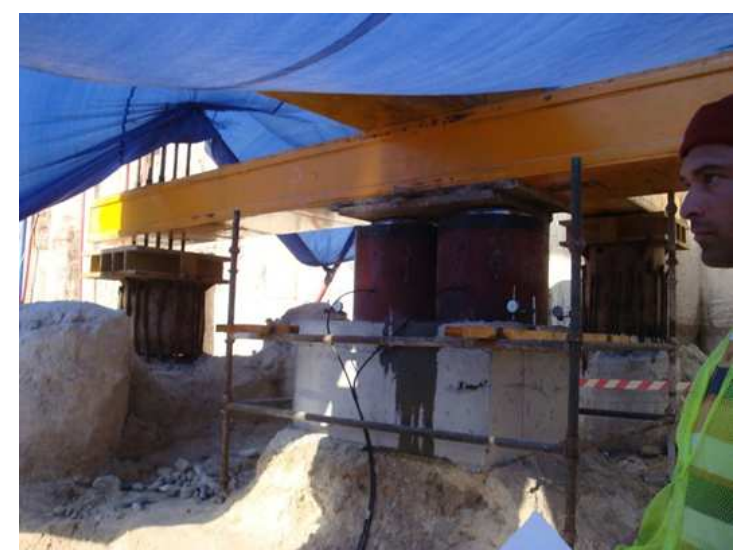

Fig. 4 Static Load test in the future Etisalat centre

Pile test data are collected from the field and will be implemented in the network. The majority of the points are to be used for training and a certain percentage of them will randomly be selected for validation. The setting of the network is empirical, however keeping the network simple is essential in order to avoid overtraining and consequently overfitting $[14,15]$. The model should be able to generalize the mapping between input and output and should be capable of predicting the output for cases not included in the training set [16]. Such network needs substantial amount of data to be trained and verified to guarantee its performance and its ability to predict the 
displacement for new pile configuration and new soil profile.

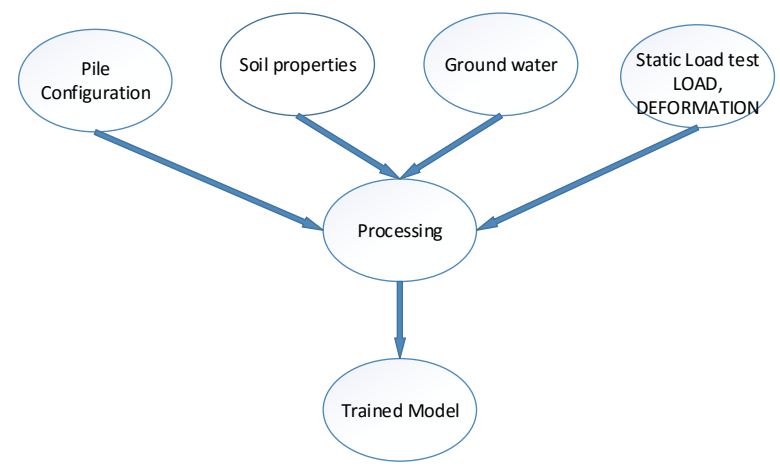

Fig. 5 Training cycle in the artificial neural network

\section{The Test Plan}

Pile behaviour is a complex process due to the many parameters controlling its performance. Predicting the pile capacity, let alone the entire load-displacement curve, has been a difficult task for geotechnical engineers and that is why the static load test is routinely conducted in the UAE. This paper introduces an artificial neural network model to predict not only the pile capacity, but the two cycles of loading-unloading static load test curves for CFA piles under compression. Although NN has been used, as discussed in section 3 in this paper, to predict the pile capacity; yet no attempt has been made to predict the entire loading-unloading curves of the static load test.

The test plan of our proposed model is that we will randomly pick a number of independent complete pile tests that are not part of the training data. We will input the geotechnical data, ground water level, pile configuration, loading cycle, and load in the model leaving the displacement field to be predicted. After training the model, three piles have $500 \mathrm{~mm}$ in diameter, and lengths $6 \mathrm{~m}, 7 \mathrm{~m}$, and $8.5 \mathrm{~m}$ will be used to test the model. These three piles will not be included in the training stage to guarantee the independency of the tests. Figure 6 shows the testing plan that will be adapted in this research. Upon the completion of the testing plan, we will use different statistical methods to compare the predicted data versus the actual field data. Coefficient of determination for example will explain relationship between the two sets of data.

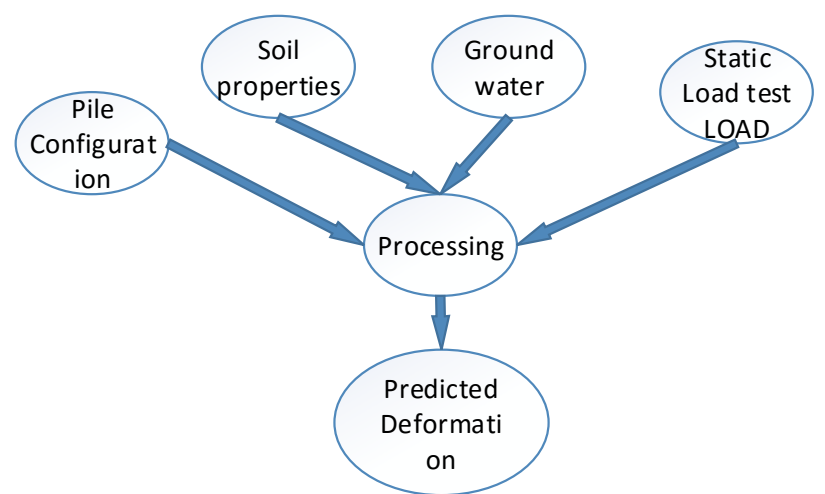

Fig. 6 Testing cycle of the artificial neural network model

\section{Conclusion}

In this paper, we introduced a new approach to predict the entire static load tests curve using artificial neural network. This approach is achievable due to three main factors; consistent geology, number of successful tests, and fixed pile diameter. The machine is fed with geotechnical data and the ground water table elevation, pile's diameter, pile's length, and load-displacement curves to train the model. Two loading and two unloading curves are to be obtained through machine learning. We believe that this approach would enable us to predict the static load test ahead of the actual field test for quality control purposes. Statistical methods such as regression models and coefficient of determination will be used to verify the model results.

\section{Acknowledgement}

The authors would like to extend their gratitude to the office of scholarship and sponsorship programs at Abu Dhabi University for their financial support of this project.

\section{References}

1. Coduto, Foundation design: Principles and practices. New Jersey: Prentice Hall, (2001)

2. Han, J., Kamber, M., Data Mining, Concepts and Techniques, 3rd ed., Morgan Kaufman Publishers, MA, USA, (2012)

3. Goh, A. T. C., Empirical design in geotechnics using Neural Networks, Geotechnique, 45, 709714, (1995)

4. Lee, I. M., Lee, J. H., Prediction of pile bearing capacity using artificial neural networks, Computers and Geotechnics, 18 (3), 189-200, (1996)

5. Abu Kiefa, M, A., General regression neural networks for driven piles in cohesionless soils, Journal of Geotechnical and Geoenvironmental Engineering - ASCE, 124 (12), 1177-1185, (1998)

6. Goh, A. T. C., Pile driving records reanalyzed using neural networks, Journal of Geotechnical and Geoenvironmental Engineering - ASCE, 122 (6) , 492-495, (1996)

7. Shahin, M. A., Jaska, M. B., and Maier, H. R., Artificial Neural Network applications in geotechnical engineering, Australian Geomechanics, March, 49-62, (2001)

8. Benali, A., Nechnech, Ammar, Prediction of the pile capacity in purely coherent soils using the approach of the artificial neural networks, In: International Seminar, Innovation \& Valorisation in Civil Engineering \& Construction Materials, $\mathrm{N}^{\circ}$ : 5O-239, University of sciences and technology, Algiers, Algeria, (2011)

9. Maizir, H., Kassim, K., 2013. Neural Network Application in Prediction of Axial Bearing 
Capacity of Driven Piles, In: Proceedings of the International Multi Conference of Engineers and Computer Scientists, Hong Kong, (2013)

10. Tarawneh, B., Pipe pile setup: Database and prediction model using artificial neural network, Soils and Foundations, 53 (4), 607-615, (2013)

11. Alzo'ubi, A. K., Ati,M., Ibrahim, F., Smart Framework for Predicting Drilled Shaft Capacity Based on Data Mining Techniques and GIS Data, In: D. Manzanal and A.O. Sfriso (Eds.), From Fundamentals to Applications in Geotechnics, The Pan American Conference on Soil Mechanics and Geotechnical Engineering, 15th PCSMGE / 8th SCRM / 6th IS-BA 2015, 15-18 November, pp. 1909-1915 (2015)

12. Fookes, P.G., Knill, J.L. The application of engineering geology in the regional development of northern and central Iran, Engineering Geology, 3, 81-120, (1969)

13. British standard, BS 8004, Code of practice for foundations, BSI, (2015)

14. Haykin, S, Neural Networks, A Comprehensive Foundation, Macmillan College Publishing Co., New York, USA, (1999)

15. Liu et al., (2008), Optimized approximation algorithm in neural networks without overfitting, IEEE Trans. Neural Networks, 19 (6), pp. 983995, (2008)

16. Geman, E. et al, Neural networks and the bias/variance dilemma, Neural Computing., 4 , pp. 1-58, (1992) 